\title{
Alcohol consumption and the risk of acute myocardial infarction in women
}

\author{
Cosetta Bianchi, Eva Negri, Carlo La Vecchia, Silvia Franceschi
}

Istituto di Ricerche Farmacologiche Mario Negri, Via Eritrea 62, 20157 Milan, Italy. C Bianchi

E Negri

C La Vecchia

Aviano Cancer

Center, 33081 Aviano

(Pordenone), Italy.

S Franceschi

Correspondence to:

Dr E Negri

Accepted for publication December 1992

\begin{abstract}
Study objective-To investigate the relationship between alcohol consumption and the risk of acute myocardial infarction in women.

Design-This was a hospital based, casecontrol study carried out between 1983 and 1990. Main outcome measures were average daily number of drinks of various alcoholic beverages consumed and corresponding multivariate relative risk estimates and $\mathbf{9 5 \%}$ confidence intervals (CI)

Setting-A network including major teaching and general hospitals in northern Italy.

Subjects-Cases were 298 women with acute myocardial infarction but no history of ischaemic heart disease and controls 685 women admitted to hospital for acute conditions, unrelated to alcohol consumption or to known or suspected risk factors for ischaemic heart disease.
\end{abstract}

Measurements and main resultsCompared with non-drinkers, the estimated relative risks $(\mathrm{RR})$ were $0.7(95 \% \mathrm{CI} 0.5,1.0)$ for one drink or less per day, 0.8 (95\% CI 0.6 , $1 \cdot 2)$ for more than one to two drinks per day, $1.4(95 \%$ CI $0.8,2.3)$ for more than two to three, and $2.6(95 \% \mathrm{CI} 1.5,4 \cdot 6)$ for more than three drinks per day. These estimates were consistent across strata of selected covariates, including age, education, and smoking. Allowance for major identified risk factors for myocardial infarction did not materially modify the risk estimate for light drinkers ( $R R \quad 0 \cdot 7,95 \%$ CI $0.5,1 \cdot 1$ ), but reduced the $R R$ in heavy drinkers to $1.8(95 \%$ CI 0.9, 3.5).

Conclusions-This study indicates that women who do not drink alcohol have a risk of myocardial infarction that is higher than that of light drinkers, although the protection of light drinking was not significant. Among drinkers, however, there was a significant direct trend in risk with dose. The raised risks in heavy drinkers may reflect a real association or result from other unfavourable char-

sumption and the risk of coronary heart disease (CHD), with moderate drinkers showing lower mortality than either abstainers or heavy drinkers. ${ }^{3-5}$

On the basis of these results, it has been suggested that moderate alcohol consumption protects against $\mathrm{CHD}$, but the interpretation of the observed relation is still controversial. ${ }^{6-9} \mathrm{~A}$ number of epidemiologically and biologically plausible mechanisms of action have been suggested, including the relation between alcohol drinking and high density lipoprotein cholesterol, apolipoproteins, fibrinolysis, coagulation factors, and blood pressure, but none has as yet been firmly established. ${ }^{10}$

For women, in particular, data on alcohol intake and the risk of CHD are sparse. ${ }^{11-15}$ Most investigations, including the Framingham Heart Study Cohort, ${ }^{4}$ the American Cancer Society One Million Study, ${ }^{16}$ and a case-control study from New Zealand, ${ }^{17}$ found similar results in men and women, although data in women, particularly for heavy drinkers, were limited. Even the large American Nurses Health Study, ${ }^{15}$ in a report based on 164 patients with non-fatal myocardial infarctions and 36 deaths from CHD, included only 16 women who drank $\geqslant 25 \mathrm{~g}$ of ethanol per day. Evidence for differences in alcohol metabolism between the two sexes (that is lower alcohol dehydrogenase activity in women than men) encourages interest in a better understanding of the nature of the relationship in women. ${ }^{1819}$

Furthermore, death certification rates from acute myocardial infarction and all ischaemic heart disease in Italian women (age standardised death rates $46 / 100000$ in 1984 , world standard $)^{2021}$ are about $50 \%$ lower than in most northern European and North American countries, where the majority of published studies have been conducted. In addition, Italian data may make an important contribution to the study of the association between alcohol intake and acute myocardial infarction in women, since alcohol drinking by women is socially accepted in Italy and, hence, is more frequent and possibly more accurately reported than in most other western countries. ${ }^{22}$ More importantly, alcohol intake may be less often under-reported. We therefore analysed the relation between alcohol intake and myocardial infarction in women using data from a case-control study conducted in northern Italy.

There is a large amount of evidence that alcohol is related to acute myocardial infarction, but the dose-risk relationship is still open to debate. In some investigations an inverse linear relationship has been described, ${ }^{1}{ }^{2}$ while others found a "J" or " $U$ " shaped relationship between alcohol con-

\section{Methods}

From January 1983, data were collected on women with acute myocardial infarction admitted to the coronary care units of 30 hospitals in 
Table I Distribution of 298 female cases of acute myocardial infarction and 685 controls according to age, education, and smoking habits. Italy, 1983-90.
Table II Distribution of 298 female cases of acute myocardial infarction and 685 controls according to alcoholic beverage consumption. Italy, 198390.

northern Italy and on comparison subjects (controls) admitted for acute conditions to the same hospitals where cases had been identified. The methods have been described in detail previously. ${ }^{23}$ The only modification introduced into the original protocol was that the upper age limit was raised from 54 to 74 years in June 1987 .

The present analysis is based on data collected before November 1990 for a total of 298 cases (aged 18-74 years, median age 50 years), defined according to the standard World Health Organization criteria for acute myocardial infarction.

Among the 685 controls (aged 17-74 years, median age 50 years), $25 \%$ were admitted for traumatic conditions, $32 \%$ for non-traumatic orthopaedic disorders (mostly low back pain and disc disorders), $19 \%$ for surgical conditions (including plastic surgery), and $24 \%$ for other illnesses (for example, acute infections, skin, ear, nose and throat diseases, or teeth disorders).

The structured questionnaire included information on sociodemographic characteristics, general lifestyle habits (for example, smoking, coffee consumption, etc), a few selected indicator foods, a problem oriented medical history, and history of selected drug usage, including oral contraceptives and female hormones for other indications. Questions on alcohol included the number of days per week each type of alcoholic

\begin{tabular}{|c|c|c|}
\hline & Myocardial infarction & Controls \\
\hline Variable & No $(\%)$ & No (\%) \\
\hline $\begin{array}{l}\text { Age: } \\
<40 \\
40-49 \\
50-59 \\
60-74\end{array}$ & $\begin{array}{r}36(12 \cdot 1) \\
106(35 \cdot 6) \\
110(36 \cdot 9) \\
46(15 \cdot 4)\end{array}$ & $\begin{array}{l}139(20 \cdot 3) \\
184(26 \cdot 9) \\
220(32 \cdot 1) \\
142(20 \cdot 7)\end{array}$ \\
\hline $\begin{array}{l}\text { Education (y): } \\
\quad<7 \\
7-11 \\
\geq 12\end{array}$ & $\begin{array}{r}185(62 \cdot 1) \\
83(27 \cdot 9) \\
30(10 \cdot 1)\end{array}$ & $\begin{array}{l}420(61 \cdot 3) \\
163(23 \cdot 8) \\
102(14 \cdot 9)\end{array}$ \\
\hline $\begin{array}{l}\text { Smoking habits: } \\
\text { Never smokers } \\
\text { Ex-smokers } \\
<20 \text { cigarettes/day } \\
\geq 20 \text { cigarettes/day }\end{array}$ & $\begin{array}{r}108(36 \cdot 2) \\
24(8 \cdot 1) \\
80(26 \cdot 8) \\
86(28 \cdot 9)\end{array}$ & $\begin{array}{r}469(68 \cdot 5) \\
39(5 \cdot 7) \\
116(16 \cdot 9) \\
61(8 \cdot 9)\end{array}$ \\
\hline
\end{tabular}

\begin{tabular}{|c|c|c|}
\hline & Myocardial infarction & Controls \\
\hline Variable & No (\%) & No (\%) \\
\hline $\begin{array}{l}\text { Wine (drinks/day): } \\
\text { Non-drinkers } \\
\leq 1 \\
>1-2 \\
>2-3 \\
>3 \\
\text { Unknown }\end{array}$ & $\begin{aligned} 126 & (42 \cdot 3) \\
61 & (20 \cdot 5) \\
69 & (23 \cdot 2) \\
22 & (7 \cdot 4) \\
19 & (6 \cdot 4) \\
1 & (0 \cdot 3)\end{aligned}$ & $\begin{array}{rr}288 & (42 \cdot 0) \\
200 & (29 \cdot 2) \\
159 & (23 \cdot 2) \\
22 & (3 \cdot 2) \\
15 & (2 \cdot 2) \\
1 & (0 \cdot 1)\end{array}$ \\
\hline
\end{tabular}

Beer: Non-drinkers $\quad 273(91.6)$ $\begin{array}{lrr}\text { Drinkers } & 273(91 \cdot 6) & 636(92 \cdot 8) \\ \text { Unt } & 25(8.4) & 48(7 \cdot 0)\end{array}$

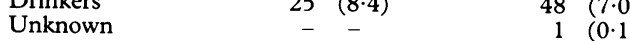

Spirits Non-drinkers $\quad 269(90 \cdot 1) \quad 653(95 \cdot 3)$

$\begin{array}{lrrr}\text { Drinkers } & 27 & (9 \cdot 1) & 32(4 \cdot 7) \\ \text { Unknown } & 2 & (0 \cdot 7) & -\end{array}$

All alcoholic beverages

(drinks/day)

Non-drinkers

$\leq 1$

$>1-2$

$>2-3$

Unknown

Duration of alcohol

consumption (y)

Non-drinker

$<30$

$\geq 30$
Unknown

$120(40 \cdot 3)$

$58(19 \cdot 5)$

$58(19.5)$

$30(10 \cdot 1)$

$30(10 \cdot 1)$

$2(0 \cdot 7)$

$278(40 \cdot 6)$

$193(28 \cdot 2)$

$145(21 \cdot 2)$

$44 \quad(6 \cdot 4)$
$24 \quad(3.5)$

$1 \quad(0 \cdot 1)$

$120(40 \cdot 3)$

$94(31 \cdot 5)$
$84(28 \cdot 2)$ beverage (wine, beer, and spirits) was consumed, the average number of drinks per day, and the duration of the habit in years.

DATA ANALYSIS AND CONTROL OF CONFOUNDING The average number of drinks per day for each type of alcoholic beverage (wine, which by itself accounted for more than $90 \%$ of all alcohol consumption in this female population, beer, and spirits), and the average total alcoholic beverage consumption were computed assuming a comparable pure alcohol content in each type of drink (that is, $150 \mathrm{ml}$ of wine $=330 \mathrm{ml}$ of beer $=30 \mathrm{ml}$ of spirits=approximately $12-15 \mathrm{ml}$ of ethanol).

Relative risks ( $R R$ of acute myocardial infarction, together with their $95 \%$ confidence intervals (CI), were first derived from data stratified for age in decades by the MantelHaenszel procedure. ${ }^{24}{ }^{25}$ To allow simultaneously for a number of potential confounding factors, unconditional multiple logistic regression was used. $^{2627}$ Included in the regression equations were terms for age; education; geographical area; smoking habits (never smokers; exsmokers; current smokers of $<20$ and $\geq 20$ cigarettes per day); body mass index; coffee consumption; history of angina, diabetes, hypertension, hyperlipidaemia; and family history of heart disease. The significance of linear trend in risk was assessed by comparing the difference between the deviances of the models with and without the variable of interest to the $\chi^{2}$ distribution with one degree of freedom. ${ }^{26}$

\section{Results}

Table I gives the distribution of cases and controls according to age, years of education, and smoking habits. The two groups were comparable with regard to years of schooling, while cases of acute myocardial infarction tended to smoke appreciably more than controls $(63.8 v 31.5 \%)$.

Table II shows the distribution of women with myocardial infarction and controls according to reported alcoholic beverage consumption and duration of the habit. Wine drinkers were equally frequent in cases and controls $(58 \%)$. There was a lower proportion of cases among light drinkers $(\leq 1$ drink/day: $21 v 29 \%$ of controls) and a higher one in women who reported drinking more than two drinks per day (14 v 5\%).

Consumption of beer and spirits was appreciably lower than wine intake in this Italian population, but cases were more frequently drinkers, especially of spirits ( $8 v 7 \%$ for beer; $9 v$ $5 \%$ for spirits). When total alcohol consumption was considered, the percentage of drinkers increased to $60 \%$ in both groups: $39 \%$ of cases $v$ $49 \%$ of controls reported two or less drinks per day while $20 \%$ of cases $v 10 \%$ of controls consumed more than two drinks per day. With reference to duration, $28 \%$ of cases and $32 \%$ of controls had been drinking for 30 years or more.

The RRs of acute myocardial infarction in relation to alcohol consumption are reported in table III. For wine consumption, the RR in non-drinkers was slightly below unity for one or less drink per day $(\mathrm{RR}=0 \cdot 7,95 \% \mathrm{CI} 0 \cdot 5,1 \cdot 0)$, but it rose to $1.0(95 \% \mathrm{CI} 0.6,1.3)$ for one to two drinks; to $1 \cdot 8(95 \%$ CI $1 \cdot 0,3 \cdot 5)$ for two to three; 
Table III Estimated relative risks $(R R)$ of acute myocardial infarction and 95\% confidence intervals (CI) in relation to selected measures of alcohol consumption. Italy 198390.

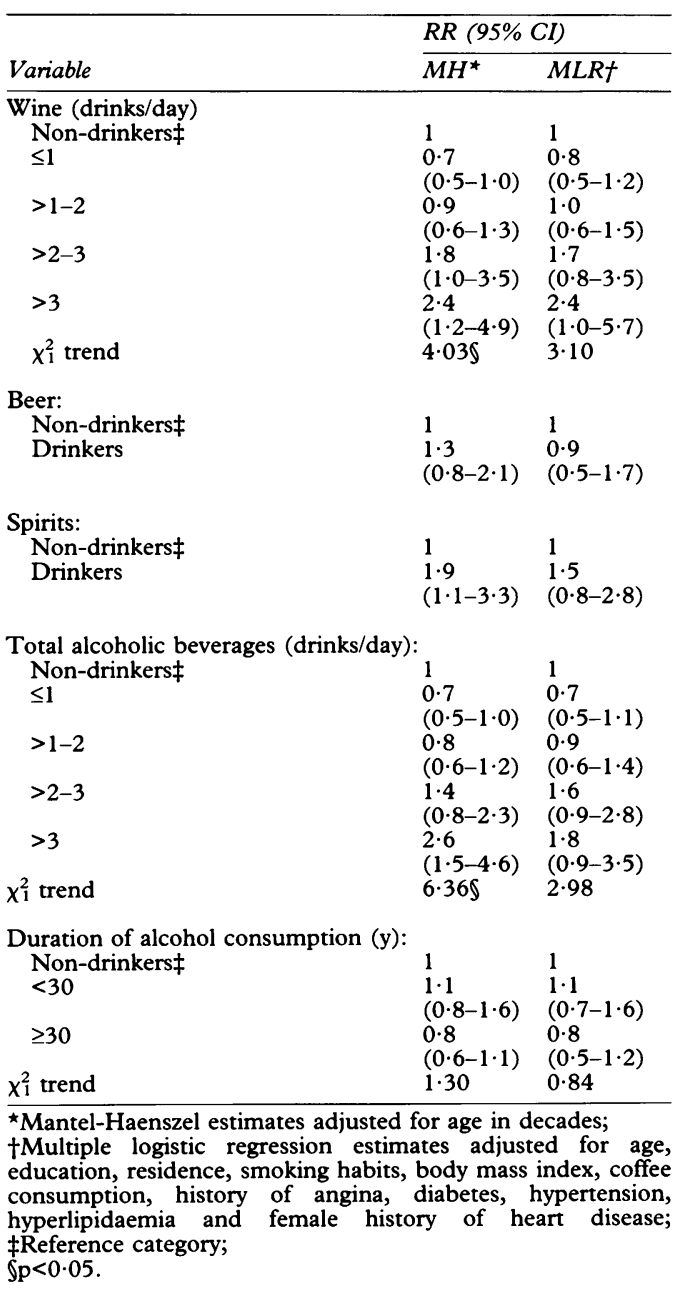

and to $2 \cdot 4(95 \%$ CI $1 \cdot 2,4 \cdot 9)$ for more than three drinks per day. The relative risks were somewhat above unity for drinkers of beer $(R R=1 \cdot 3,95 \% \mathrm{CI}$ $0 \cdot 8,2 \cdot 1)$ or spirits $(R R=1 \cdot 9,95 \%$ CI $1 \cdot 1,3 \cdot 3)$ compared with those who did not drink alcohol. The risks for total alcohol consumption were similar to those for wine only, being $0 \cdot 7,0.8,1.4$, and 2.6 for subsequent levels of intake compared with non-drinkers.

Adjustment for smoking and a number of other potentially relevant covariates, including education, area of residence, body mass index, coffee consumption, history of angina, diabetes, hypertension, hyperlipidaemia, and heart disease reduced the estimated risk for heavy drinkers (more than three drinks per day) from $2 \cdot 6$ to $1 \cdot 8$. However, it had no appreciable influence on the risk estimates for other levels $(R R=0.7$ for one or less; 0.9 for one to two; 1.6 for more than two to three drinks per day). Likewise, multivariate RRs decreased to $0.9(95 \% \mathrm{CI} 0.5,1.7)$ for beer drinkers and to 1.5 (95\% CI $0.8,2 \cdot 8)$ for spirit drinkers versus non-drinkers. The trends in risk for wine and total alcohol consumption including alcohol abstainers were not statistically significant, but were significant when the analysis was restricted to drinkers.

The duration of alcohol consumption showed no association with the risk of myocardial infarction, the RR estimates being $1 \cdot 1$ for less than 30 years and 0.8 for 30 years or more with respect to non-drinkers. Those estimates were not modified by allowance for identified potential confounding factors.

Table IV gives the RRs for total alcohol consumption in separate strata of age, education, and smoking. The risks for light consumption of alcohol (up to one drink per day) were below unity, ranging from 0.4 to 0.9 , whereas those for heavy alcohol intake were consistently above unity, ranging from 1.8 to 2.4 across the strata of various covariates. Thus, compared with nondrinkers, the RRs were 1.9 for those both below and above age 50 years; 2.4 in less and 1.8 in more educated women; $2 \cdot 0$ for never smokers, $2 \cdot 1$ for moderate smokers, and 1.8 for heavy smokers.

\section{Discussion}

This study of myocardial infarction in women showed a somewhat higher risk in non-drinkers than in light drinkers, but an increasing risk with increasing alcohol consumption in women who drank alcohol: the RR was above unity for more than two alcoholic drinks per day. The interest of these data on heavier levels of drinking in women may be related to the indication that gastric alcohol hydrogenase activity is lower in women than in men, thus leading to increased bioavailability of ethanol in women. ${ }^{18}$

A possible limitation of this study is the use of hospital controls, whose strengths and limitations for the analysis of lifestyle habits have long been debated. ${ }^{24}$ Still, we excluded from the control group patients admitted for diseases potentially or definitely related to alcohol drinking. Lack of total exclusion of alcohol-related diseases, if anything, would have tended to underestimate the association for heavy drinkers.

Although recall bias and a certain amount of under-reporting cannot be entirely dismissed, it is reasonable to believe that cases and controls should not have reported their consumption differently, since alcohol drinking in Italy is socially acceptable in women. It has been shown, moreover, that simple questionnaires can assess alcohol consumption reasonably well. ${ }^{28}$
Table IV Estimated relative risk ${ }^{*}$ of acute myocardial infarction in relation to average daily total alcoholic beverage consumption in separate strata of age and selected covariates. Italy, 19831990.

\begin{tabular}{|c|c|c|c|c|c|c|}
\hline \multirow[b]{2}{*}{ Covariate } & \multicolumn{6}{|c|}{ Total alcoholic beverage consumption (drinks per day) } \\
\hline & Non-drinkerst & $\leq 1$ & $>1-2$ & $>2-3$ & $>3$ & $\chi_{t}^{2}($ trend $)$ \\
\hline $\begin{array}{l}\text { Age: } \\
\quad<50 \\
\geq 50\end{array}$ & $\begin{array}{l}1 \\
1\end{array}$ & $\begin{array}{l}0.7 \\
0.6\end{array}$ & $\begin{array}{l}1 \cdot 1 \\
0.6\end{array}$ & $\begin{array}{l}1 \cdot 0 \\
1 \cdot 2\end{array}$ & $\begin{array}{l}1.9 \\
1.9\end{array}$ & $\begin{array}{l}1.5 \\
0.2\end{array}$ \\
\hline $\begin{array}{l}\text { Education: } \\
\quad<7 \\
\geq 7\end{array}$ & $\begin{array}{l}1 \\
1\end{array}$ & $\begin{array}{l}0.9 \\
0.4\end{array}$ & $\begin{array}{l}0.8 \\
1.0\end{array}$ & $\begin{array}{l}1.0 \\
1.3\end{array}$ & $\begin{array}{l}2.4 \\
1.8\end{array}$ & $\begin{array}{l}0.9 \\
1.2\end{array}$ \\
\hline $\begin{array}{l}\text { Smoking habits: } \\
\text { Never/ex-smoker } \\
\text { Current-<20 cigarettes/day } \\
\text { Current- } \geq 20 \text { cigarettes/day }\end{array}$ & $\begin{array}{l}1 \\
1 \\
1\end{array}$ & $\begin{array}{l}0.7 \\
0.6 \\
0.7\end{array}$ & $\begin{array}{l}0.9 \\
0.8 \\
0.7\end{array}$ & $\begin{array}{l}0.9 \\
1.2 \\
1.4\end{array}$ & $\begin{array}{l}2 \cdot 0 \\
2 \cdot 1 \\
1 \cdot 8\end{array}$ & $\begin{array}{l}0.2 \\
1.8 \\
0.3\end{array}$ \\
\hline
\end{tabular}

* Estimates from multiple logistic regression. Allowance was made for age, education and smoking †Reference category. 
In addition, in this study cases and controls came from comparable catchment areas, participation was almost complete, and allowance for major identified potential confounding factors did not change materially the alcohol related $R R$ estimates. In particular, no difference was evident between age adjusted and multivariate analysis for light drinkers.

A possible explanation for the apparently higher risk of myocardial infarction in non-drinkers is that the group of alcohol abstainers included subjects who were already ill or were at high risk of heart disease for other reasons. In a British cohort of over 7700 men, ${ }^{29}$ ex-drinkers and non-drinkers were more frequently unmarried, and had the highest prevalence rates of angina, electrocardiographic abnormalities, high blood pressure, and several other chronic conditions. Light drinkers may have a complex of multiple advantageous characteristics such as lower smoking levels, higher social class, more physical activity, and a healthier diet. This does not necessarily apply to the Italian population, however, where moderate drinking, for instance, tends to be more common in lower social class women. ${ }^{22}$

Multivariate analysis can partly, but not completely, take into account these potential differences in baseline characteristics. Our findings of an apparently higher risk in abstainers compared with light drinkers also agree with most previous studies of chronic heart disease in men and women. ${ }^{12} 1530$

The American Nurses' Health Study ${ }^{15}$ found a non-significant inverse linear trend in risk between alcohol consumption and coronary heart disease. In the Framingham study, ${ }^{412}$ women in the highest alcohol consumption category $(>30 \mathrm{~g}$ of ethanol per day) had a non-significant reduced risk of coronary heart disease relative to nondrinkers. These results are only apparently inconsistent with our findings of an increasing risk with dose in drinkers, since these American studies had limited information on high alcohol consumption.

Thus, a major strength and interest of this study is the information not only on light and moderate alcohol consumption, but also on intermediate and higher levels of intake in women. Most studies suggesting protective effects of alcohol on myocardial infarction in women, in fact, had information restricted to below two or three drinks per day. The apparent discrepancies with our findings, if not due to chance or bias, should thus be viewed against the different alcohol drinking patterns and baseline characteristics of the Italian population, whose mortality from acute myocardial infarction is considerably lower than in north America and most European countries. ${ }^{20-22}$

This work was conducted within the framework of the CNR (Italian National Research Council) applied project "Prevention and control of disease factors". The generous contributions of the Italian Association for
Cancer Research, of the Italian League against Cancer, Milan, and of Mrs Angela Marchegiano Borgomainerio are gratefully acknowledged. The authors thank Mrs Judy Baggott, Mrs Paola Bonifacino, and the GA Pfeiffer Memorial Library Staff for helpful editorial assistance.

1 Miller GJ, Beckkles GLA, Maude GH, Carson DC. Alcohol consumption: Protection against coronary heart disease and risks to health. Int f Epidemiol 1990; 19: 923-30.

2 Rimm EB, Giovannucci EL, Willett WC, et al. Prospective study of alcohol consumption and risk of coronary disease in men. Lancet 1991; 338: 464-8.

3 Marmot MG, Rose G, Shipley MJ, Thomas BJ. Alcohol and mortality: A U-shaped curve. Lancet 1981; i: 580-3.

4 Aronson Friedman L, Kimball AW. Coronary heart disease mortality and alcohol consumption in Framingham. $A m \mathcal{F}$ Epidemiol 1986; 124: 481-9.

5 Kittner SJ, Garcia-Palmieri MR, Costas R Jr, Cruz-Vidal M, Kittner SJ, Garcia-Palmieri MR, Costas R Jr, Cruz-Vidal M,
Abbott RD, Havlik RJ. Alcohol and coronary heart disease Abbott RD, Havlik RJ. Alcohol and coronary heart disea
in Puerto Rico. Am $\mathcal{F}$ Epidemiol 1983; 113: 536-50.

in Puerto Rico. Am $\mathcal{f}$ Epidemiol 1983; 113: 536-50.
6 Editorial. Alchohol and mortality: The myth of the U-shaped curve. Lancet 1988; ii: 1292-3.

Cullen K. Alcohol and mortality. Lancet 1991; 337: 363-4. Shaper AG. Alcohol and mortality. Lancet 1991; 337: 911-12.

9 Klatsky AL, Armstrong MA, Friedman GD. Relations of alcoholic beverage use to subsequent coronary artery disease hospitalization. Am $\mathcal{F}$ Cardiol 1986; 58: 710-14.

10 Moore RD, Pearson TA. Moderate alcohol consumption and coronary artery disease. A review. Medicine 1986; 65: 242-67.

11 Klatsky AL, Freidman GD, Siegelaub AB. Alcohol consumption before myocardial infarction: results from the Kaiser-Permanente epidemiologic study of myocardial infarction. Ann Intern Med 1974; 81: 294-301.

12 Stason WB, Neff RK, Miettinen OS, Jick H. Alcohol consumption and nonfatal myocardial infarction. $A m \mathcal{F}$

13 Cullen K, Stenhouse NS, Wearne KL. Alcohol and mortality in the Busselton study. Int F Epidemiol 1982; 11: 67-70.

14 Rosenberg L, Slone D, Shapiro S, Kaufman DW, Miettinen OS, Stolley PD. Alcoholic beverages and myocardia infarction in young women. Am $\mathcal{F}$ Public Health 1981; 71 82-5.

15 Stampfer MJ, Colditz GA, Willett WC, Speizer FE Hennekens $\mathrm{CH}$. A prospective study of moderate alcohol consumption and the risk of coronary disease and stroke in women. N Engl f Med 1988; 319: 267-73.

16 Boffetta P, Garfinkel L. Alcohol drinking and mortality among men enrolled in an American Cancer Society prospective study. Epidemiolgy 1990; 1: 342-8.

17 Jackson R, Scragg R, Beaglehole R. Alcohol consumption and risk of coronary heart disease. BMF 1991; 303: 21 1-16.

18 Schenker S, Spegg KV. The risk of alcohol intake in men and women. All may not be equal. N Engl f Med 1990; 322: $127-9$

19 Frezza M, di Padova C, Pozzato G, Terpin M, Baraona E, Leiber CS. High blood alcohol levels in women. The role of decrease gastric alcohol dehydrogenase activity and firstpass metabolism. N Engl f Med 1990; 322: 95-9.

20 Uemura K, Pisa Z. Trends in cardiovascular disease mortality in industrialized countries since 1950. World Health Stat $Q$ 1988; 41 : 155-78.

21 La Vecchia C, Negri E, Decarli A. The onset of decline in ischemic heart disease in Italy. Am $\mathcal{F}$ Public Health 1990; 80; 502.

22 La Vecchia C, Pagano C, Negri E, Decarli A. Determinants of alcohol consumption in Italy. Int $\mathcal{f}$ Epidemiol 1987; 16: 295-6.

23 La Vecchia C, Franceschi S, Decarli A, et al. Risk factors for myocardial infarction in young women. Am $\mathcal{F}$ Epidemiol 1987; 125: 832-43

24 Mantel N, Haenszel W. Statistical aspects of the analysis of data from retrospective studies of disease. $\mathcal{F}$ Natl Cancer Inst 1959; 22: 719-48.

25 Mantel N. Chi square tests with one degree of freedom. Extension of the Mantel-Haenszel procedure. $\mathcal{F} \mathrm{Am}$ Stat Assoc 1963; 58: 690-700.

26 Breslow NE, Day NE. Statistical methods in cancer research Vol. 1. The analysis of case control studies. Lyon: IARC Sci Publ, 1980: 325-38.

27 Baker RJ, Nelder JA. The GLIM system. Release 3. Oxford: Numerical Algorithms Group, 1978.

28 Giovannucci E, Colditz G, Stampfer MJ, et al. The assessment of alcohol consumption by a simple selfadministered questionnaire. Am f Epidemiol 1991; 133: 810-17.

29 Shaper AG, Wannamethee G, Walker M. Alcohol and mortality in British men: Explaining the U-shaped curve. Lancet 1988; ii: 1267-73.

30 Marmot M, Brunner E. Alcohol and cardiovascular disease: The status of the U shaped curve. BMF 1991; 303: 565-8. 